Case Report

\title{
ACE Inhibitor-Induced Angioedema following Cervical Spine Surgery
}

\author{
Faris Hannoodi and Hussam Sabbagh \\ Wayne State University, Detroit, MI, USA \\ Correspondence should be addressed to Faris Hannoodi; fh.saint@hotmail.com \\ Received 24 October 2016; Accepted 16 February 2017; Published 28 February 2017 \\ Academic Editor: Assad Movahed
}

Copyright (C) 2017 Faris Hannoodi and Hussam Sabbagh. This is an open access article distributed under the Creative Commons Attribution License, which permits unrestricted use, distribution, and reproduction in any medium, provided the original work is properly cited.

\begin{abstract}
Angioedema is a well-known side effect of angiotensin converting enzyme inhibitors (ACEi). However, ACE inhibitors induced angioedema after cervical surgery is a rare condition. They result in increased levels of circulating bradykinins. Rare cases of angioedema following local trauma in patients using ACE inhibitors have been published. We present such a case. A 54-yearold Caucasian female with a history significant for hypertension, controlled with lisinopril, was admitted for routine cervical spine surgery. She has severe degenerative cervical disc disease and was admitted to the hospital for an elective cervical diskectomy. The patient failed weaning off the ventilator on multiple attempts postoperatively. There were no observed symptoms of an allergic reaction. A CT scan of the neck showed extensive soft tissue edema at the level of the arytenoids. Dexamethasone was given to reduce the edema without successful resolution. On review of her medications, it was found that the patient was resumed on lisinopril following the procedure. It was subsequently discontinued. By the following day the patient had a positive leak around the ET tube cuff and patient was successfully extubated.
\end{abstract}

\section{Introduction}

Angioedema is a well-known side effect of angiotensin converting enzyme inhibitors (ACEi). Angioedema occurs because ACE inhibitors impair bradykinin degradation, leading to increase in bradykinin levels. Bradykinin in turn leads to increased vasodilation and vascular permeability, resulting in angioedema. Mast cells are not involved in this pathway. As a result, histamine is not produced, therefore symptoms of pruritus and urticaria do not present.

ACE inhibitor-induced angioedema tends to involve the periorbital region and structures within the oral cavity, oropharynx, and larynx [1,2]. ACE inhibitor-induced angioedema after cervical surgery is a rare condition. A few cases of angioedema following local trauma in patients using ACE inhibitors have been published [3-7]. We present an interesting case of severe angioedema causing airway obstruction after anterior cervical surgery in a patient using ACE inhibitors.

\section{Case Report}

A 54-year-old Caucasian female with a medical history significant for hypertension, hyperlipidemia, cervical disc disease, and depression was admitted for routine cervical spine surgery. She has never smoked and does not drink alcohol. Her medications included lisinopril $10 \mathrm{mg}$, atorvastatin $40 \mathrm{mg}$, citalopram $20 \mathrm{mg}$, and furosemide $20 \mathrm{mg}$. She has severe degenerative disk disease at C4-C7, with herniated nucleus pulposus. The patient was admitted to hospital for an elective cervical disk arthroplasty with diskectomy at $\mathrm{C} 4$ to $\mathrm{C} 7$ and fusion at $\mathrm{C} 5-\mathrm{C} 7$.

The patient failed weaning off the ventilator on multiple attempts postoperatively. There were no observed symptoms of an allergic reaction. Her vital signs and laboratory tests were unremarkable. CT scan of the neck showed extensive edema at the level of the arytenoids, but no retropharyngeal hematoma or abscess were noted (Figure 1). A bronchoscopy confirmed arytenoid edema. 


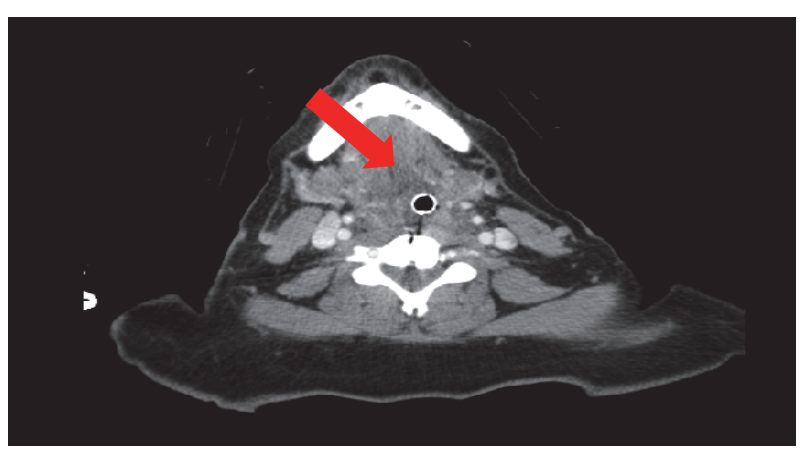

Figure 1: Soft tissue edema demonstrated around the endotracheal tube.

Dexamethasone $8 \mathrm{mg}$ was given every 6 hours for 4 days to reduce the edema without successful resolution. On review of her medications, it was found that the patient was on lisinopril following the procedure for the treatment of hypertension. It was subsequently discontinued. The following day, the patient was weaned and successfully extubated.

\section{Discussion}

In our case the surgery most likely resulted in marked bradykinin release in a patient who was already on an ACE inhibitor. The release of bradykinin, in addition to decreased bradykinin catabolism as a result of ACE inhibitor therapy, has precipitated angioedema. The definitive treatment of angioedema is to completely stop the offending medication, in this case lisinopril.

There are several risk factors that can contribute to ACE inhibitor-induced angioedema, including previous angioedema, age above 65, NSAID use, female sex, smoking, seasonal allergies, certain immunosuppressants (sirolimus and everolimus), underlying $\mathrm{Cl}$ inhibitor deficiency or dysfunction, history of ACE inhibitor-induced cough, and surgery [8-10]. The relevant risk factors to our case are female sex and surgery, though no further testing was carried out to look for $\mathrm{Cl}$ inhibitor deficiency.

The areas affected by ACE inhibitor-induced angioedema are the face, mouth, upper airway, and intestine. In the reported cases where angioedema occurred following surgical procedures, the affected areas involved the oral cavity and upper airway [5-7]. This is likely due to local trauma as a result of the cervical spinal surgery. This is consistent with reviewed literature since head and neck surgery appear to increase the incidence of ACE inhibitor-induced angioedema to the oropharynx and upper airway. Of the three surgical cases reported, two required definitive airways to be present to prevent airway compromise, one of which failed intubation and required a tracheotomy $[5,7]$. Only one reported case did not require intubation to secure the airway [6].

The mainstay of management is to secure the airway, discontinue the ACE inhibitor, and give systemic steroids. Other additions can include giving epinephrine and antihistaminics [5]. Persistent symptoms may require synthetic bradykinin B2-receptor antagonist. In the reviewed cases, however, the management was similar to that of our case. The airway was secured and systemic steroids were given. In one case, Benadryl and epinephrine were administered as angioedema was treated as an allergic reaction. In another case systemic steroids were given for a period of 7 days for complete resolution [5-7].

\section{Conclusion}

To sum up, although ACE inhibitor-induced angioedema is rare in the surgical setting, the complications can be lifethreatening. ACE inhibitors should be discontinued in ALL patients undergoing neck surgery, regardless of the presence of specific risk factors. There is no sense in taking any risks.

\section{Competing Interests}

The authors declare that they have no competing interests.

\section{References}

[1] A. Agostoni and M. Cicardi, "Drug-induced angioedema without urticaria incidence, prevention and management," Drug Safety, vol. 24, no. 8, pp. 599-606, 2001.

[2] D. C. Kuo and R. A. Barish, "Isolated uvular angioedema associated with ACE inhibitor use," Journal of Emergency Medicine, vol. 13, no. 3, pp. 327-330, 1995.

[3] B. Brent Simmons, M. A. Folsom, L. A. Bryden, and J. S. Studdiford, "Angioedema after local trauma in a patient on angiotensin-converting enzyme inhibitor therapy," The Journal of the American Board of Family Medicine, vol. 21, no. 6, pp. 577$579,2008$.

[4] H. Homma, J. Aoki, and K. Tanabe, "Life-threatening angioedema after primary percutaneous coronary intervention," Internal Medicine, vol. 54, no. 8, pp. 999-1000, 2015.

[5] K. U. E. Ogbureke, C. Cruz, J. V. Johnson, and J. F. Helfrick, "Perioperative angioedema in a patient on long-term angiotensin-coverting enzyme (ACE)-inhibitor therapy)," Journal of Oral and Maxillofacial Surgery, vol. 54, no. 7, pp. 917-920, 1996.

[6] M. M. Marrocco-Trischitta, G. Melissano, D. De Dominicis, and R. Chiesa, "Angiotensin-converting enzyme inhibitor-induced angioedema following carotid endarterectomy misdiagnosed as cervical hematoma," Annals of Vascular Surgery, vol. 20, no. 1, pp. 145-147, 2006.

[7] M. J. Krnacik and M. H. Heggeness, "Severe angioedema causing airway obstruction after anterior cervical surgery," Spine, vol. 22, no. 18, pp. 2188-2190, 1997.

[8] J. B. Kostis, H. J. Kim, J. Rusnak et al., "Incidence and characteristics of angioedema associated with enalapril," Archives of Internal Medicine, vol. 165, no. 14, pp. 1637-1642, 2005.

[9] M. Duerr, P. Glander, F. Diekmann, D. Dragun, H.-H. Neumayer, and K. Budde, "Increased incidence of angioedema with ACE inhibitors in combination with mTOR inhibitors in kidney transplant recipients," Clinical Journal of the American Society of Nephrology, vol. 5, no. 4, pp. 703-708, 2010.

[10] J. B. Byrd, K. Touzin, S. Sile et al., "Dipeptidyl peptidase IV in angiotensin-converting enzyme inhibitor-associated angioedema," Hypertension, vol. 51, no. 1, pp. 141-147, 2008. 


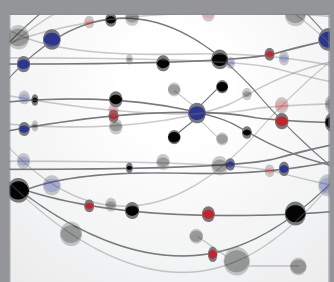

The Scientific World Journal
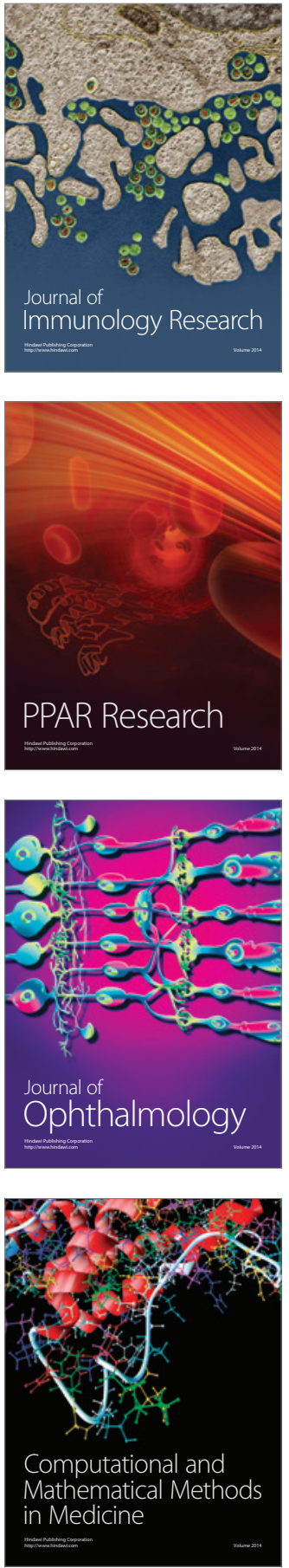

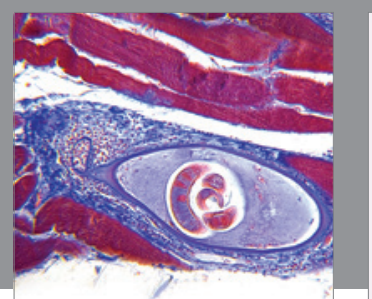

Gastroenterology Research and Practice
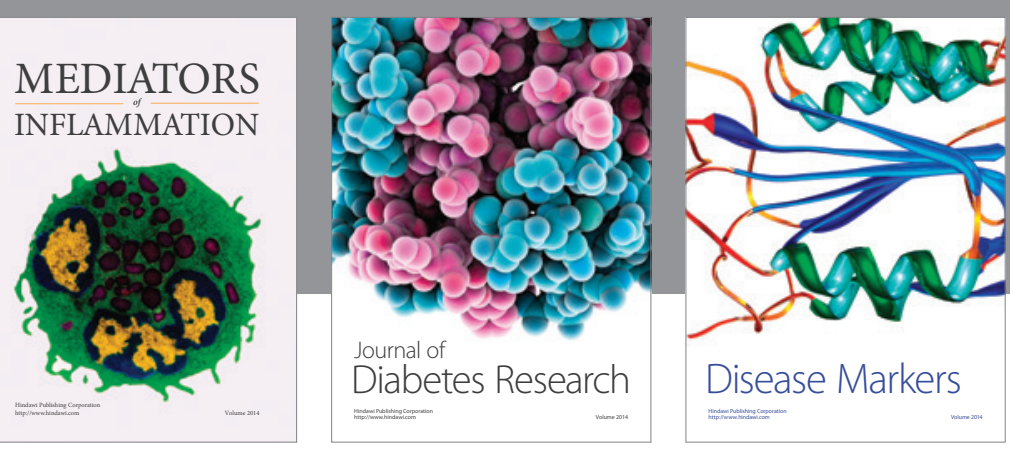

Disease Markers

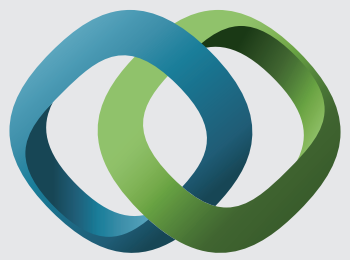

\section{Hindawi}

Submit your manuscripts at

https://www.hindawi.com
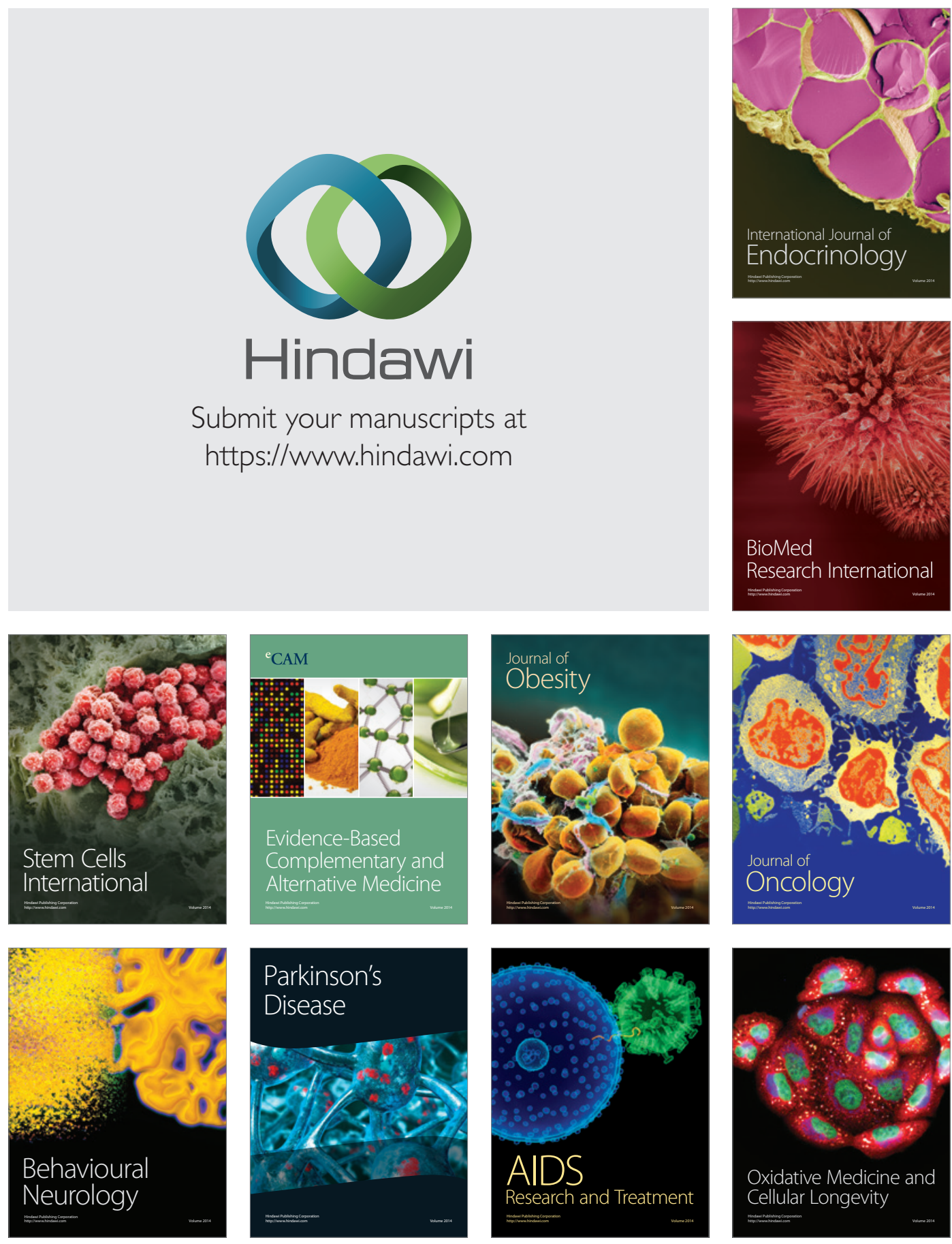